\title{
Escherichia coli Thymine Auxotrophs Suppressible by Carbon Dioxide
}

\author{
By J. W. DALE ${ }^{*}$ AND J. T. SMITH ${ }^{2}$ \\ ${ }^{1}$ Department of Microbiology, University of Surrey, Guildford, Surrey GU2 $5 X H, U K$ \\ ${ }^{2}$ Microbiology Section, Department of Pharmaceutics, School of Pharmacy, \\ University of London, Brunswick Square, London WCIN IAX, UK
}

(Received 31 May 1984 ; revised 31 October 1984)

\begin{abstract}
Two independently-isolated thymine-requiring mutant strains of Escherichia coli were found to possess an unusual phenotype : in the presence of $\mathrm{CO}_{2}$, growth was independent of thymine. The two strains showed different profiles of temperature sensitivity. Glycine, serine and methionine were unable to relieve the thymine-dependence. Both strains were susceptible to trimethoprim under conditions where they were thymine-independent. The results are consistent with the occurrence of partial defects in thymidylate synthase.
\end{abstract}

\section{INTRODUCTION}

The normal pathway of thymine biosynthesis is by methylation of deoxyuridylate (dUMP) to produce deoxythymidylate (dTMP). This reaction is catalysed by thymidylate synthase (EC 2.1.1.45) and is accompanied by the conversion of one molecule of 5,10-methylenetetrahydrofolate to dihydrofolate. Reactivation of the folate co-substrate is accomplished by dihydrofolate reductase (EC 1.5.1.3); this enzyme is the site of action of the antibacterial agent trimethoprim.

Mutant strains which are defective in thymidylate synthase require exogenous thymine for growth. Simultaneously, the absence of the thymidylate synthase reaction abolishes the need for dihydrofolate reductase and hence also abolishes trimethoprim sensitivity (Amyes \& Smith, 1975). Resistance to trimethoprim can be used as a convenient way of selecting thyminerequiring auxotrophs in the laboratory (Stacey \& Simson, 1965). This paper describes the properties of two independently isolated mutants in which thymine dependence can be suppressed by a $\mathrm{CO}_{2}$-enriched environment.

\section{METHODS}

Bacterial strains. The bacterial strains used are listed in Table 1.

Media. The minimal medium (DM) used throughout was that described by Davis \& Mingioli (1950) with glucose $\left(2 \cdot 8 \mathrm{~g}^{-1}\right)$ as carbon source (except that where indicated lactose was used at the same concentration). Supplements were used where appropriate at the following concentrations: nicotinic acid $\left(5 \mathrm{mgl}^{-1}\right)$, DLmethionine ( $\left.50 \mathrm{mg} \mathrm{l}^{-1}\right)$, L-histidine $\left(40 \mathrm{mg} \mathrm{l}^{-1}\right)$, thymine $\left(60 \mathrm{mg} \mathrm{l}^{-1}\right)$, trimethoprim $\left(4 \mathrm{mg} \mathrm{l}^{-1}\right)$. For disc diffusion sensitivity testing, Diagnostic Sensitivity Test agar (Oxoid) was used with the addition of $6 \%(v / v)$ lysed horse blood. $\mathrm{CO}_{2}$ incubation was obtained by use of a candle jar or a $\mathrm{CO}_{2}$ incubator. All tests of growth requirements were carried out on solid media by streaking to single colony density with a wire loop.

Isolation of thymine-requiring mutants. The procedure used was that described by Pinney \& Smith (1973). Mutant colonies were purified on selective (trimethoprim/thymine) minimal agar before use.

\section{RESULTS AND DISCUSSION}

The first of the two strains was isolated following the routine application of the trimethoprim selection procedure in order to obtain a thymine-requiring mutant of Escherichia coli 114 . The proportion of spontaneous trimethoprim-resistant bacteria in the culture was of the order of $10^{-7}$. Of the 70 colonies obtained, 8 were picked at random and purified on minimal agar 


\section{Table 1. Bacterial strains}

Strain Relevant characters Source/reference

Escherichia coli

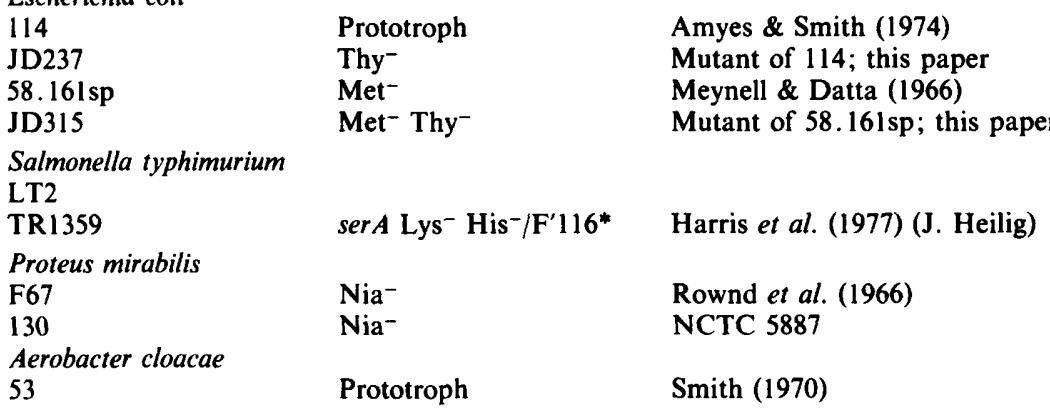

* Phenotypically Ser+ Lys $^{+} \mathrm{His}^{-}$due to complementation of $\operatorname{serA}$ and Lys ${ }^{-}$by the plasmid.

Table 2. Growth requirements of E. coli strains JD237 and JD315

\begin{tabular}{|c|c|c|c|c|c|c|c|c|}
\hline \multirow{2}{*}{$\begin{array}{l}\text { Growth } \\
\text { conditions }\end{array}$} & \multirow[b]{2}{*}{ Incubation temp. } & \multicolumn{4}{|c|}{ Strain JD237 } & \multicolumn{3}{|c|}{ Strain JD315* } \\
\hline & & $25^{\circ} \mathrm{C}$ & $30^{\circ} \mathrm{C}$ & $37^{\circ} \mathrm{C}$ & $44^{\circ} \mathrm{C}$ & $25^{\circ} \mathrm{C}$ & $30^{\circ} \mathrm{C}$ & $37^{\circ} \mathrm{C}$ \\
\hline Minimal medium DM & & + & + & - & - & - & - & - \\
\hline $\mathrm{DM}+$ thymine & & + & + & + & - & + & + & + \\
\hline $\mathrm{DM}+\mathrm{CO}_{2}$ & & + & + & + & - & + & + & - \\
\hline $\mathrm{DM}+$ glycine & & ND & + & - & - & ND & ND & ND \\
\hline $\mathrm{DM}+$ serine & & ND & + & - & - & ND & ND & ND \\
\hline $\mathrm{DM}+$ methionine & & ND & + & - & - & ND & ND & ND \\
\hline DM anaerobic & & ND & ND & - & ND & ND & ND & ND \\
\hline $\begin{array}{l}\text { Trimethoprim } \\
\text { sensitivity: }\end{array}$ & & & & & & & & \\
\hline$+\mathrm{CO}_{2}$ & & $\mathbf{s}$ & $\mathbf{s}$ & $\mathbf{s}$ & NG & $\mathbf{s}$ & $\mathbf{s}$ & NG \\
\hline$-\mathrm{CO}_{2}$ & & $\mathbf{s}$ & $\mathbf{s}$ & NG & NG & NG & NG & NG \\
\hline
\end{tabular}

supplemented with thymine and trimethoprim. A single colony of one of the isolates was then picked for further use and assigned the strain number JD237. This strain was later found to be temperature sensitive in its thymine requirement, being able to grow in the absence of thymine at $30^{\circ} \mathrm{C}$. Other workers have found that a considerable proportion of $\mathrm{Thy}^{-}$mutants of $E$. coli are temperature sensitive (O’Donovan \& Neuhard, 1970). Subsequently, a further unexpected property of strain JD237 was accidentally discovered, viz. that it can grow at $37^{\circ} \mathrm{C}$ in the absence of thymine provided it is grown in an environment containing $5 \%(\mathrm{v} / \mathrm{v}) \mathrm{CO}_{2}$.

The growth requirements of strain JD237 are summarized in Table 2: it requires added thymine or $\mathrm{CO}_{2}$ or a reduced growth temperature. None of the other supplements tested was able to permit growth under 'normal' conditions, i.e. $37^{\circ} \mathrm{C}$ in air without thymine. Strain JD237 is unable to grow at $44^{\circ} \mathrm{C}$ even with thymine or $\mathrm{CO}_{2}$ added. Table 2 also shows that this strain is fully sensitive to trimethoprim (using the parent strain 114 as the control organism) under all the conditions where it is phenotypically $\mathrm{Thy}^{+}$; under conditions where thymine is required (and the organism would be expected to be resistant to trimethoprim) it is unable to grow on the sensitivity test medium, which is the typical behaviour of thymine-requiring organisms.

Thymine-requiring auxotrophs are normally defective in thymidylate synthase, yet it seems unlikely that the addition of $\mathrm{CO}_{2}$ would have any direct effect on this enzyme; the absence of suppression by anaerobic conditions indicates that the effect is not due to an oxygen-labile enzyme. $\mathrm{CO}_{2}$ is involved directly in earlier stages of the thymine synthesis pathway, in 
particular in the carbamoyl phosphate synthetase reaction. However, a mutation at this site (car) would result in a defect in the production of pyrimidines generally. Furthermore, this step is also involved in arginine biosynthesis and car mutants normally require both arginine and uracil (Pierard et al., 1965). A further test of growth requirements was therefore carried out with each of the following supplements in turn (each at $30 \mathrm{mg} \mathrm{l}^{-1}$ ): uracil, uridine, deoxyuridine, cytosine, cytidine, deoxycytidine, arginine, and arginine plus uracil. None of these was able to substitute for thymine in permitting growth at $37^{\circ} \mathrm{C}$, in air. It therefore seems unlikely that a defect in the car gene could be involved in this case.

An alternative site for the defect in strain JD237 could be in the regeneration of the 5,10methylenetetrahydrofolate needed as co-substrate for the synthesis of thymidylate; the main route for this is the serine hydroxymethyltransferase reaction which is coupled to the conversion of serine to glycine. The $\mathrm{CO}_{2}$ effect would then operate by providing an alternative route for generating 5,10-methylenetetrahydrofolate. If this were the case, it might be expected that other substrates involved in one carbon metabolism would also produce a similar effect; but none of those tested (methionine, glycine and serine) was able to substitute for thymine.

The evidence then points towards the defect in this strain being in the thymidylate synthase gene, as with other thymine auxotrophs. It should therefore be complemented by a plasmid carrying a wild-type thy A allele such as $\mathrm{F}^{\prime} 116$ (Harris et al., 1977). The donor strain used was Salmonella typhimurium TR1359. After an overnight mating in nutrient broth, the bacteria were washed and plated on unsupplemented minimal medium, with lactose as sole carbon source to provide additional counterselection against the donor organism. Prototrophic recombinants were obtained, at a frequency of $10^{-6}$ per recipient. In the absence of the donor, no Thy ${ }^{+}$ revertants of $E$. coli JD237 were isolated. This indicates, but does not prove, that the lesion in JD237 can be complemented by a wild-type thy $A$ allele, or by some other gene present on $F^{\prime} 116$.

In order to establish whether the $\mathrm{CO}_{2}$ effect is a widespread phenomenon, other thyminerequiring mutants were tested; these included derivatives of $S$. typhimurium LT2, Proteus mirabilis strains 130 and F67, Aerobacter cloacae 53 and $E$. coli 58.161 sp. These all showed the usual phenotype: thymine was required for growth, whether $\mathrm{CO}_{2}$ was present or not. Further thymine-requiring mutants were then generated by the trimethoprim selection procedure and tested for their ability to grow at $37^{\circ} \mathrm{C}$ in the absence of thymine, in $\mathrm{CO}_{2}$. Six mutants of E. coli 114 , four mutants of $E$. coli $58.161 \mathrm{sp}$ and four mutants of $S$. typhimurium were all unaffected by the presence of $\mathrm{CO}_{2}$ at $37^{\circ} \mathrm{C}$. However, one of the mutants of E. coli 58.161sp (JD315) was subsequently shown to have a temperature-sensitive $\mathrm{CO}_{2}$-suppressible phenotype, which differs from that of JD237 (Table 2). Whereas JD237 was prototrophic at temperatures below $30^{\circ} \mathrm{C}$, and showed $\mathrm{CO}_{2}$-suppressible thymine-dependence at $37^{\circ} \mathrm{C}$, JD315 could not grow on minimal medium at any of the temperatures tested (as is normal for $\mathrm{Thy}^{-}$strains), but the thymine requirement in this strain was suppressed by $\mathrm{CO}_{2}$ at $25^{\circ} \mathrm{C}$ or $30^{\circ} \mathrm{C}$. At $37^{\circ} \mathrm{C}, \mathrm{CO}_{2}$ could not suppress the thymine requirement of strain JD315. As with other strains, JD315 was trimethoprim-sensitive under conditions where it was phenotypically $\mathrm{Thy}^{+}$.

No firm conclusion can yet be drawn about the nature of the genetic defect in strains JD237 and JD315. The most likely explanation is that the mutations in these strains are in the thy $A$ gene, as in other thymine-requiring auxotrophs; the difference is that in these two cases, instead of abolishing the activity of the thymidylate synthase, the mutations result in more subtle changes in the properties of the enzyme so that its effectiveness is influenced by the indirect effects of $\mathrm{CO}_{2}$ on the one-carbon metabolism of the cell.

We would like to thank Mrs S. Wall and Miss K. Holdsworth for invaluable technical assistance and the Wellcome Research Laboratories for their donation of trimethoprim.

\section{REFERENCES}

Amyes, S. G. B. \& Smith, J. T. (1974). Trimethoprim action and its analogy with thymine starvation. Antimicrobial Agents and Chemotherapy 5, 169-178.
Amyes, S. G. B. \& Smith, J. T. (1975). Thymineless mutants and their resistance to trimethoprim. Journal of Antimicrobial Chemotherapy 1, 85-89. 
Davis, B. D. \& Mingioli, E. S. (1950). Mutants of Escherichia coli requiring methionine or vitamin B12. Journal of Bacteriology 60, 17-28.

Harris, J. D., Martinez, I. I. \& Calendar, R. (1977). A gene from Escherichia coli affecting the sigma subunit of RNA polymerase. Proceedings of the National Academy of Sciences of the United States of America 74, 1836-1840.

Meynell, E. \& DatTA, N. (1966). The nature and incidence of conjugation factors in Escherichia coli. Genetical Research 7, 141-148.

O'Donovan, G. A. \& Neuhard, J. (1970). Pyrimidine metabolism in micro-organisms. Bacteriological Reviews 34, 278-343.

Pierard, A., Glansdorff, N., Mergeay, M. \& WIAME, J. M. (1965). Control of the biosynthesis of carbamoyl phosphate in Escherichia coli. Journal of Molecular Biology 14, 23-36.

PinNey, R. J. \& SMITH, J. T. (1973). Joint trimethoprim and sulphamethoxazole resistance in bacteria infected with R factors. Journal of Medical Microbiology 6, 13-19.

Rownd, R., Nakaya, R. \& Nakamura, A. (1966). Molecular nature of the drug resistance factors of the Enterobacteriaceae. Journal of Molecular Biology 17, 376-393.

SmITH, J. T. (1970). Penicillinase in two strains of Aerobacter cloacae isolated from the same patient. Guy's Hospital Reports 119, 173-183.

STACEY, K. A. \& SimSON, E. (1965). Improved method for the isolation of thymine-requiring mutants of Escherichia coli. Journal of Bacteriology 90, 554-555. 